\title{
Effects of research disturbance on nest survival in a mixed colony of waterbirds
}

\author{
Jocelyn Champagnon ${ }^{\text {Corresp., } 1}$, Hugo Carré ${ }^{1}$, Lisa Gili ${ }^{1}$ \\ ${ }^{1}$ Tour du Valat, Research institute for conservation of Mediterranean wetlands, Arles, France \\ Corresponding Author: Jocelyn Champagnon \\ Email address: champagnon@tourduvalat.org
}

Background. Long-term research is crucial for the conservation and development of knowledge in ecology; however, it is essential to quantify and minimize any negative effects associated with research to gather reliable and representative long-term monitoring data. In colonial bird species, chicks are often marked with coded bands in order to assess demographic parameters of the population. Banding chicks in multi-species colonies is challenging because it involves disturbances to species that are at different stages of progress in their reproduction.

Methods. We took advantage of a long term banding program launched on Glossy lbis (Plegadis falcinellus) breeding in a major mixed colony of herons in Camargue, southern France, to assess the effect of banding operation disturbance on the reproductive success of the three most numerous waterbirds species in the colony. Over two breeding seasons (2015 and 2016), 336 nests of Glossy Ibis, Little Egrets (Egretta garzetta) and Cattle Egrets (Bubulcus ibis) were monitored from a floating blind in two zones of the colony: one zone disturbed twice a year by the banding activities and another not disturbed (control zone). We applied a logistic-exposure analysis method to estimate the daily survival rate (DSR) of nests and chicks aged up to three weeks.

Results. Daily survival rate of Glossy Ibis was reduced in the disturbed zone while DSR increased for Little and Cattle Egrets in the disturbed zone. Nevertheless, DSR was not reduced on the week following the banding, thus discarding a direct effect of handling on breeding success of Glossy lbis. The protocol and statistical analysis presented here are robust and can be applied to any bird species to test for the effect of a research disturbance or other short and repeated temporal events that may affect reproductive success over one or more breeding seasons. 
3 Jocelyn Champagnon ${ }^{1}$, Hugo Carré ${ }^{1}$, Lisa Gili ${ }^{1}$

$4{ }^{1}$ Tour du Valat, Research Institute for Conservation of Mediterranean Wetlands, Le Sambuc, 5 Arles, France

7 Corresponding Author:

8 Jocelyn Champagnon ${ }^{1}$

9 Tour du Valat, Le Sambuc, 13200 Arles, France

10 Email address: champagnon@tourduvalat.org

12 Abstract

13 Background. Long-term research is crucial for the conservation and development of knowledge

14 in ecology; however, it is essential to quantify and minimize any negative effects associated with research to gather reliable and representative long-term monitoring data. In colonial bird species, chicks are often marked with coded bands in order to assess demographic parameters of the population. Banding chicks in multi-species colonies is challenging because it involves disturbances to species that are at different stages of progress in their reproduction.

Methods. We took advantage of a long term banding program launched on Glossy Ibis (Plegadis falcinellus) breeding in a major mixed colony of herons in Camargue, southern France, to assess the effect of banding operation disturbance on the reproductive success of the three most numerous waterbirds species in the colony. Over two breeding seasons (2015 and 2016), 336 nests of Glossy Ibis, Little Egrets (Egretta garzetta) and Cattle Egrets (Bubulcus ibis) were monitored from a floating blind in two zones of the colony: one zone disturbed twice a year by the banding activities and another not disturbed (control zone). We applied a logistic-exposure analysis method to estimate the daily survival rate (DSR) of nests and chicks aged up to three 27 weeks. 
28 Results. Daily survival rate of Glossy Ibis was reduced in the disturbed zone while DSR

29

36 increased for Little and Cattle Egrets in the disturbed zone. Nevertheless, DSR was not reduced on the week following the banding, thus discarding a direct effect of handling on breeding success of Glossy Ibis. The protocol and statistical analysis presented here are robust and can be applied to any bird species to test for the effect of a research disturbance or other short and repeated temporal events that may affect reproductive success over one or more breeding seasons.

\section{Introduction}

7 Human activities including hunting (Madsen \& Fox, 1995), recreation (Navedo \& Herrera, 2012), ecotourism (Klein, Humphrey \& Percival, 1995; Guillemain et al., 2008; Monti et al., 2018) and even birdwatching (Kronenberg, 2014) can have negative impacts on birds. Yet, the potential effects of ornithological research are less well understood. The aim of conservation research studies is generally to contribute to our knowledge about the studied species. When undertaking this research, it is necessary to take into account disturbance by researchers in order to minimize the effects on the studied population (Carney \& Sydeman, 1999). Nevertheless, disturbance is rarely assessed numerically and it is expressed in language that is open to interpretation (Wilson \& McMahon, 2006)

Research activities that may lead to reduced nest survival (Götmark, 1992; Fair, Paul \& Jones, 2010), are particularly a concern as this can influence the outcome of breeding directly through nest desertion (Tremblay \& Ellison, 1979; Piatt, Roberts \& Hatch, 1990; Shealer \& Haverland, 2000; Criscuolo, 2001) or indirectly through an elevated risk of suffering nest predation (Ibáñez-Álamo, Sanllorente \& Soler, 2012). Evidences of negative impacts exist but they are largely dependent on taxa and the timing involved. For instance, nest desertion occurs 
52 more frequently at an early stage of incubation in Black-crowned night herons (Nycticorax

53 nycticorax, Tremblay and Ellison 1979). In a relatively recent study, Ibáñez-Álamo et al. (2012)

54 provide some meta-analytical evidence suggesting that research-induced disturbances may not 55 necessarily involve increase nest predation. common practice (Spotswood et al., 2012). Bird banding and other capture activities may induce stress to the handled bird and the surrounding individuals. This has influenced many countries to require the activities to be performed by trained and licensed ornithologists (Romero \& Romero, 2002; Balmer et al., 2008). Despite the risks involved, it is often assumed that studies arising from so called capture-recapture data lead to a wide variety of information surpassing the potential risk to the animals.

64 chicks in multi-species colonies is even more challenging because not all species are synchronized, causing disturbances of species with different ecology and sensitivity. There have been recommendations for minimizing investigator's disturbance in this context (Carney \&

67 Sydeman, 1999). In the context of a large mixed colony of waterbirds, Götmark (1992) recommended to act rapidly to avoid extreme climatic conditions. Nevertheless, to our knowledge, effect of banding operations in a mixed colony of waterbirds has not been assessed numerically, neither on the breeding success of the species banded, nor on the other species in

71 the colony that are not targeted by the banding activities. Here we described an experimental study investigating the effects of research-induced

73 disturbance caused by regular banding operations of Glossy Ibis (Plegadis falcinellus) chicks

74 located in large, heron-mixed colonies made up of hundreds of breeding pairs. By conducting 
75 regular monitoring of the colony from a floating blind that provided non-disturbing entries to the

76 colony (Figure 1), we were able to assess the effect of research activities on reproductive

77 success.

78

79 Materials \& Methods

80 Study Area

81 This study was carried out in a 3 ha heronry situated in an inundated wood of French Tamarisk

82 trees (Tamarix gallica), in the Scamandre Natural Regional Reserve, located in western

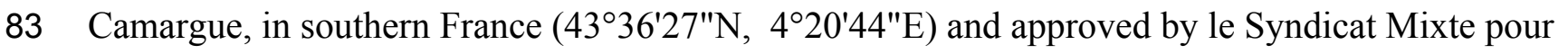

84 la protection et la gestion de la Camargue Gardoise. This heronry is currently the largest mixed

85 heron colony in France and one of the largest in Europe (Gauthier-Clerc, Kayser \& Petit, 2006).

86 Since 2005, the total number of pairs breeding in the heronry (including Glossy Ibis and herons)

87 fluctuated between 3,000 and 9,000 pairs. During 2015, the heronry was composed of 3,700

88 Cattle Egrets (Bubulcus ibis), 3,255 Little Egrets (Egretta garzetta), 1,028 Glossy Ibis breeding

89 pairs, 669 Black-crowned night herons (Nycticorax nycticorax), 371 Squacco herons (Ardeola

90 ralloides) and 46 Grey herons (Ardea cinerea).

91

92 Banding operations

93 The study took place over two consecutive breeding seasons, between April and July of 2015 and

94 2016. Two comparable zones of approximately $400 \mathrm{~m}^{2}$ were chosen based on their similarity in

95 terms of vegetation density, wind exposure and observer accessibility. One zone was disturbed

96 due to the regular banding operations (disturbed zone), while the other was not (control zone).

97 The two zones were separated by at least $50 \mathrm{~m}$ of vegetation. Banding operations occurred twice

98 in each season and each operation involved capturing and banding Glossy Ibis chicks between 10 
99 days and three weeks of age (Figure 1). The operations were conducted early in the morning

100 when meteorological conditions were deemed favorable (i.e., with no wind and a temperature

101 above $15^{\circ} \mathrm{C}$ ). During each operation, 28 to 36 participants entered the colony and were divided

102 into five to seven teams, each supervised by an official bander (Figure 1). All participants were

103 briefed on the methods before entering the colony and operations were limited to a maximum

104 duration of 1 hour. During this time, between 123 and 365 chicks were captured in their nests,

105 handled for banding, measuring and weighing, and finally returned to their nest by the handler.

106 Neighboring chicks from others species were not touched. During the course of each banding

107 operation, both zones (disturbed and control) were visually monitored by an observer hidden

108 inside a floating blind (Figure 1) at a distance of 5 to 10 meters and within a range of ten

109 monitored nests. The behavior of the breeding adults of each zone was monitored. All banding

110 operations were approved and supervised by the French Biological Research Center for Bird

111 Populations (Centre de Recherches sur la Biologie des Populations d'Oiseaux,

112 https://crbpo.mnhn.fr/).

113

114 Breeding success monitoring

115 Within each zone (disturbed and control), all nests of Cattle Egrets, Little Egrets and Glossy Ibis

116 were identified within 11 randomly selected Tamarisk trees. For each nest, we recorded the zone,

117 the tree, the nesting species and the height of the nest in accordance with the following

118 categories: $<1 \mathrm{~m}$ above the water, $1-2 \mathrm{~m}$ above the water and $>2 \mathrm{~m}$ above the water. Higher nests

119 did not exceed $3 \mathrm{~m}$ in height.

120

Nests were monitored from a mobile floating blind (Figure 1) that allowed smooth

121 movements of the observer over the entire colony without altering the behavior of the birds. With 
122 this method, it was possible to monitor the nests from a distance of approximately two meters.

123 Monitoring took place two to three times a week, between $07 \mathrm{~h} 30$ and $19 \mathrm{~h} 30$, alternating morning

124 and afternoon sessions. The first incursion to the site took place approximately two weeks after

125 the colony was established and at least two weeks before the first banding operation took place

126 (Figure 2).

127 We considered that a nest survived between visits when at least one chick or egg was

128 seen in the nest, or a breeder was attending the nest. A nest was considered to be abandoned

129 when it was seen to be destroyed, empty or without an attending breeder over two successive

130 sessions. The observer also noted the number of eggs and/or chicks seen in each nest and their

131 respective age considering three age classes: 0-7 days old, 8-14 days old and 15-21 days old. As

132 in other colonial waterbird species, classing of further ages was not possible because beyond the

133 age of three weeks high mobility makes it difficult to attribute the chicks to a specific nest

134 (Frederick \& Collopy, 1989a; Herring et al., 2010).

135

136 Statistical analysis

137 We assessed breeding success by means of the daily survival rate (DSR) of each nest (i.e., the

138 probability that a nest was active at a certain point in time). In order to account for the higher

139 probabilities of breeding success that are expected whenever a nest is monitored late in the

140 season (due to the fact that the observer is not able to document failures occurred before the

141 monitoring initiates; Mayfield, 1975; Jones \& Geupel, 2007), we applied the logistic-exposure

142 method developed for this purpose (Shaffer, 2004).

143 We considered the following fixed covariates as potential explanatory variables for the

144 fate of a nest: day of the year (continuous), height of the nest in the tree (categorical with three 
145 levels: low, medium and high), species (categorical with three levels: Little Egret, Cattle Egret

146 and Glossy Ibis), zone (two levels: control vs. disturbed), and banding week (the seven-day

147 period following a banding operation, a categorical covariate with two levels). Additionally, we

148 considered the following interactions of interest: height $\mathrm{x}$ species, height $\mathrm{x}$ zone, species $\mathrm{x}$ zone,

149 zone $\mathrm{x}$ banding week, banding week $\mathrm{x}$ species. In order to account for the dependency between

150 the nests within a given tree, as well as the effect of year, we used the effect of tree (categorical

151 with 11 levels each year) nested in that of year (categorical with two levels) as a random

152 intercept. The linear predictor for our most general model was:

153

$$
\log _{e}\left(\frac{s_{i j k}}{1-s_{i j k}}\right)
$$

$$
\begin{aligned}
& =\text { Day }_{i j k}+\text { Height }_{i j k}+\text { Species }_{i j k}+\text { Zone }_{i j k}+\text { BandingWeek }_{i j k}+\text { Height }_{i j k} \times \\
& \text { Species }_{i j k}+\text { Height }_{i j k} \times \text { Zone }_{i j k}+\text { Species }_{i j k} \times \text { Zone }_{i j k}+\text { Zone }_{i j k} \\
& \times \text { BandingWeek }_{i j k}+\text { BandingWeek }_{i j k} \times \text { Species }_{i j k}+\text { Year }_{j}+\text { Tree }_{k(j)}
\end{aligned}
$$

154

$$
\operatorname{Year}_{j} \sim N\left(0, \sigma_{\text {Year }}^{2}\right)
$$

155

$$
\operatorname{Tree}_{k(j)} \sim N\left(0, \sigma_{\text {Tree }}{ }^{2}\right)
$$

where $s_{i j k}$ is the daily survival rate of nest $i$ during year $j$ in tree $k$.

The package lme4 (Bates et al., 2015) in the software R (R Core Team, 2017) was used to

fit the 144 candidate models that all had biological meaning. We performed automated model-selection routines using the package MuMIn (Barton, 2018) to rank the models by their

When a more in-depth examination of the effect of a variable was required, we tested for

(Wickham, 2016) 


\section{Results}

167 Monitoring of breeders during the banding operations confirmed that in the control zone,

168 breeders of all species (not only the Glossy Ibis) tended to remain in their nests, or at close

169 proximity. Meanwhile, in the disturbed zone almost all breeders fled their nests and stayed away

170 during the banding operation, only coming back after the banding operation was finished (all

171 within 20 min after the team's retreat).

172 Over the two breeding seasons, 336 nests were monitored in the two zones, accounting

173 for a total of 2,772 observations and a mean of 9.3 observations per nest (range: 2 -19) until a

174 success or a failure event was recorded.

175 Seven models for the estimation of daily survival rate were found within $\Delta \mathrm{AICc}<2$

176 (Table 1). The seven models included an effect of the day in the season, with a DSR of nests

177 showing a linear decrease throughout the breeding period $(\beta=-0.04 \pm 0.01 \mathrm{SE}, z$ value $=-4.14$,

$178 P$-value $<0.001)$. All seven models also included an effect of species as well as the height of the

179 nest above the water. DSR was found to be lowest for the nests situated less than $1 \mathrm{~m}$ above the

180 water as compared to those situated between $1 \mathrm{~m}$ and $2 \mathrm{~m}$ high (from the third model, the most

181 parsimonious one with no interaction with species: $\beta=1.08 \pm 0.31 \mathrm{SE}, z$ value $=3.46, P$ -

182 value $=0.001)$, or to those situated more than $2 \mathrm{~m}$ above the water $(\beta=0.95 \pm 0.37 \mathrm{SE}$,

$183 z$ value $=2.54, P$-value $=0.01)$. The interaction between species and height was present in four

184 of the seven models. Results are illustrated in Figure 3. An adverse effect of banding operations

185 for Glossy Ibis chicks was suggested by three of the seven preferred models, with lower DSR for

186 Glossy ibises breeding in the disturbed zone as compared to the control zone, but a positive

187 effect was given on the two others species (Figure 4). Complementary models run from

188 subsamples of the data from the disturbed zone and the control zone showed that lower survival 
189

190

191

192

193

194 195

196

197

\section{Discussion}

199

200

201

202

203

204 205

206

207

208

209

210

211

rates for Glossy Ibis nests compared to Little Egret nests and Cattle Egret nests was found in the disturbed zone (Glossy Ibis nests vs. Cattle Egret nests: $\beta=-1.12 \pm 0.42$ SE, z value $=-2.70$, Pvalue $=0.02$ and Glossy Ibis nests vs. Little Egret nests: $\beta=-1.02 \pm 0.37 \mathrm{SE}, \mathrm{z}$ value $=-2.74, \mathrm{P}-$ value $=0.02)$ but not in the control zone (model with species variable was not retained as preferred model, see supplementary material). Nevertheless, three of the seven models refuted a temporal negative effect of the banding operations: DSR was found to be higher in the weeks following a banding operation (from fourth preferred model in Table1: $\beta=0.18 \pm 0.23 \mathrm{SE}$, $z$ value $=0.76 .19, P$-value $=0.45)$

We found no evidence of major research-induced disturbances owing to regular banding operations on a mixed-species colony of breeding tree-nesting waterbirds. Factors most affecting the success of nests were the timing of breeding, with a decline in success over the season and the relative height at which nests were situated in the trees, with a reduced survival for those that were lowest and closest to the water. Our results, however, did suggest a weak effect of research disturbance on the breeding success of Glossy Ibises, but no such effect was present in neighboring nests of Little or Cattle Egrets. Daily survival rates of Glossy Ibis nests was 4.0\% lower in the zone that was disturbed by the operations as compared to the control zone; however, further examination revealed the effect lacked statistical significance.

$$
\text { Mechanisms underlying the occurrence of any potential negative effects provoked by }
$$
research in this study, such as those observed in the Glossy Ibis, remain largely unclear. First, it is possible that any negative effects that are confined to this species are themselves a direct result of being the only species of the three that was handled and manipulated during the banding 
212 operations. However, we would have then expected to observe a reduction in the breeding

213 success of this species over the days that followed each of the banding operations, something that

214 did not occur (see the results from the models where the variable banding week was retained).

215 This absence of effect was found by Davis Jr. and Parsons (1991) in a comparison of the fate of

216 repeated handling of Snowy Egret (Egretta thula) every two days prior to banding, with

217 individuals only handled once when banded.

218 Alternatively, disturbance provoked by the operations may have indirectly affected the

219 survival of nests of Glossy Ibis by either (i) increasing the nest abandonments, or (ii) increasing

220 the risk of nest predation in the following days after the banding operation. Increased nest

221 abandonments seem an unlikely cause given that on-site monitoring of breeders during the

222 banding operations showed that all parents returned to their nests, independently of which

223 species, within the $20 \mathrm{~min}$ following retreat of all participants from the colony.

224 It is well known that nest predation can increase with human disturbance in other contexts

225 (Veen, 1977), for instance along recreational trails (Miller, Knight \& Miller, 1998). Similarly, in

226 this study we cannot rule-out the possibility that the researcher's activities and disturbance inside

227 the colony may have attracted aerial predators like the Marsh Harrier (Circus aeruginosus) or the

228 Magpie (Pica pica). If this was the case however, we would thus have expected all three species

229 to be similarly affected by the presence of such predators, and maybe even lower breeding

230 success in higher nests; the opposite of what we found in this study.

231 A reduced survival rate for the nests that were low and close to the water was found.

232 This was especially true for Glossy Ibis and Little Egret, but not for Cattle Egrets which only had

$2334 \%$ of their nests below 1 meter. It was unlikely that lower survival of lower nests was driven by

234 the banding operations because there was no effect of the interaction height $\mathrm{x}$ zone. Nevertheless, 
235 we cannot discard an effect of the floating blind, the observer being closer to lowest nests than

236 the higher ones, potentially creating disturbance non detected by the observer. Further studies

237 with a similar protocol but with increased levels of observations per week might allow

238 confirming or discarding the effect of the floating blind.

239 Finally, we cannot discard that the power of the statistical tests was not sufficient to

240 detect an adverse effect of the disturbance. The experimental protocol involved only one

241 disturbed and one control zone each year, a quite limited amount of replicates. However, it is

242 worth noting that we ruled out the possibility of a site effect because the position of the control

243 site switched with the disturbed site between the two years.

244 Interestingly, nesting success slightly increased for Little Egret and Cattle Egret nests in

245 the disturbed zone, where the nest success of Glossy Ibis tended to decrease. This result may be

246 explained by the complex level of inter-specific interactions among the birds in the heronry's

247 trees. Exclusion of Little Egret individuals by established Cattle Egrets has been shown by Dami,

248 Bennetts \& Hafner, (2006), although this occurred in the absence of Glossy Ibis individuals.

249 Here it seems that the relatively lower breeding success of the Glossy Ibis, the primary species

250 nesting in this colony, benefitted the Little Egret $(+1.7 \%$ in DSR), and to a lesser extent, the

251 Cattle Egret $(+0.8 \%$ in DSR).

252 In this study, we carried out an experimental disturbance treatment of low magnitude and

253 frequency (i.e. two banding operations limited to one hour per breeding season). This protocol is

254 in accordance with the one developed in 1982 by expert ornithologists (Hoffmann, Hafner \&

255 Salathe, 1996). Nevertheless, it can be considered as low disturbance compared to other studies

256 such as the Black-crowned Night Heron (Nycticorax nycticorax) which can include up to 15

257 visits of $45 \mathrm{~min}$ to $4 \mathrm{~h}$ conducted by Tremblay \& Ellison (1979). Such major disturbances were 
258 found to discourage new breeders, increase nest abandonment in particular during egg laying 259 periods and increase nestling mortality.

The experimental protocol and the statistical treatment that we adopted for this study

261 enabled us to test the effects of specific temporal events such as occurrence of research-related

262 disturbance on the estimation of breeding success simultaneously on three different species of

263 tree-nesting waterbirds. Contrary to more typical estimates like the number of fledglings per

264 nest, DSR allowed us to test for the effect of a temporal event. Specifically, in our study, adding

265 a temporal covariate BandingWeek allowed us to discard the effect of handling on the survival of

266 Glossy Ibis chicks.

267

\section{Conclusions}

269 Over the last century, research disturbance in ornithology has mainly focused on

270 waterbirds (Goering \& Cherry, 1971; Frederick \& Collopy, 1989b; Davis Jr. \& Parsons, 1991;

271 Götmark, 1992; Bowman et al., 1994; Kuiken et al., 1997; Carney \& Sydeman, 1999; Nisbet,

272 2000). Nevertheless, Passeriformes were over-represented in the meta-analysis on research

273 disturbance by Ibáñez-Álamo et al. (2012) because they considered that most of the studies

274 involving waterbird species (and all comprising Pelicaniformes) "included only anecdotal

275 evidence or were not properly designed to investigate this topic". It is clear that in order to

276 overcome this limitation, and also because contrasting results may arise depending on the

277 taxonomic group examined, highly effective experimental studies for waterbirds are needed. This 278 study contributes to this with the numerical assessment of research disturbance on waterbirds.

279 In this study we showed at least partial evidence for negligible effects of banding

280 operations on colonial tree-nesting waterbirds. Banding of birds for the purposes of population

281 monitoring and individual identification is an ubiquitous ornithological practice that has proven 
282 extremely helpful to assess demographic parameters of countless wild bird populations (Santoro,

283 Green \& Figuerola, 2016; Champagnon et al., 2018). However, before committing resources and

284 substantial efforts to start using them it is important to not only assess issues like whether the

285 fitted devices lead to reliable demographic parameters, but also that the banding operations

286 themselves do not compromise survival and reproduction in any meaningful way (Saraux et al.,

287 2011; Spotswood et al., 2012; Griesser et al., 2012; Guillemain et al., 2015b,a; Weiser et al.,

288 2016; Stein et al., 2017; Avila-Villegas, 2018; Border et al., 2018). We advocate that any study

289 involving manipulation of animals should consider potential adverse effects based on the

290 literature first. Animal care and ethics committees, as well as national banding organizations that

291 delivered permits for scientific studies involving wild animals, participate in updated guidelines

292 that take into account the kind of study provided here (Casper, 2009; Fair et al., 2010;

293 "Guidelines for the treatment of animals in behavioural research and teaching," 2018).

294

295 Acknowledgements

296 We warmly thank Lisa Ernoul and Oscar Sanchez Macouzet for improving the language and

297 useful comments made on a earlier version of the manuscript. We are indebted to Thomas

298 Blanchon, Yves Kayser, Jérémiah Petit, and Rémi Tiné for their advice during the design and the

299 implementation of the experiment. We thank the Syndicat Mixte pour la protection et la gestion

300 de la Camargue Gardoise for giving access to the nature reserve. We thank all the participants

301 that participated to banding operations of Glossy Ibis since 2006.

302

303 References

304 Avila-Villegas S. 2018. The jaguar and the PhD. PLOS Biology 16:e2004152. DOI:

$305 \quad$ 10.1371/journal.pbio.2004152. 
306 Balmer DE, Coiffait L, Clark J, Robinson RA, ornithology B trust for. 2008. Bird Ringing: $a$ 307 concise guide. British Trust for Ornithology Thetford.

308 Barton K. 2018. MuMIn: Multi-Model Inference.

309 Bates D, Mächler M, Bolker B, Walker S. 2015. Fitting Linear Mixed-Effects Models Using 310 lme4. Journal of Statistical Software 67:1-48. DOI: 10.18637/jss.v067.i01.

311 Border JA, Atkinson LR, Henderson IG, Hartley IR. 2018. Nest monitoring does not affect 312 nesting success of Whinchats Saxicola rubetra. Ibis 160:624-633. DOI: 10.1111/ibi.12574.

314 315

Bowman T, Thompson S, Janik C, Dubuc L. 1994. Nightlighting minimizes investigator disturbance in bird colonies. Colonial Waterbirds 17:78-82. DOI: 10.2307/1521384.

Burnham KP, Anderson DR. 2002. Model selection and multimodel inference: a practical information-theoretic approach. New York, NY: Springer-Verlag.

Carney KM, Sydeman WJ. 1999. A review of human disturbance effects on nesting colonial waterbirds. Waterbirds: The International Journal of Waterbird Biology 22:68. DOI: $10.2307 / 1521995$.

Casper RM. 2009. Guidelines for the instrumentation of wild birds and mammals. Animal Behaviour 78:1477-1483. DOI: 10.1016/j.anbehav.2009.09.023.

Champagnon J, Lebreton J-D, Drummond H, Anderson DJ. 2018. Pacific Decadal and El Niño oscillations shape survival of a seabird. Ecology 99:1063-1072. DOI: 10.1002/ecy.2179.

Criscuolo F. 2001. Does blood sampling during incubation induce nest desertion in the female common eider somateria mollissima? Marine Ornithology 29:47-50. 
327 Dami L, Bennetts RE, Hafner H. 2006. Do Cattle Egrets Exclude Little Egrets from Settling at 328 Higher Quality Sites within Mixed-species Colonies? Waterbirds 29:154-162. DOI: 329

Davis Jr. WE, Parsons KC. 1991. Effects of investigator disturbance on the survival of Snowy 10.1675/1524-4695(2006)29[154:DCEELE]2.0.CO;2.

332 333 335

336

337

338

339

340

341

342

343

344

345

346

347

348 egret nestlings. Journal of Field Ornithology 4:432-435.

Fair JM, Paul E, Jones J (eds.). 2010. Guidelines to the Use of Wild Birds in Research. Washington, D.C.

Fair JM, Paul E, Jones J, Clark AB, Davie C, Kaiser G. 2010. Guidelines to the use of wild birds in research. :215.

Frederick PC, Collopy MW. 1989a. Nesting success of five ciconiiform species in relation to water conditions in the Florida Everglades. The Auk 106:625-634.

Frederick PC, Collopy MW. 1989b. Researcher Disturbance in Colonies of Wading Birds: Effects of Frequency of Visit and Egg-Marking on Reproductive Parameters. Colonial Waterbirds 12:152. DOI: 10.2307/1521335.

Gauthier-Clerc M, Kayser Y, Petit J. 2006. Une colonie exceptionnelle de hérons arboricoles en Camargue gardoise. Ornithos 13:320-322.

Goering DK, Cherry R. 1971. Nestling mortality in a Texas heronry. The Wilson Bulletin 83:303-305.

Götmark F. 1992. The effects of investigator disturbance on nesting birds. In: Power DM ed. Current Ornithology. Boston, MA: Springer US, 63-104. DOI: 10.1007/978-1-47579921-7_3.

Griesser M, Schneider NA, Collis M-A, Overs A, Guppy M, Guppy S, Takeuchi N, Collins P, Peters A, Hall ML. 2012. Causes of Ring-Related Leg Injuries in Birds - Evidence and 

10.1371/journal.pone.0051891.

352 Guidelines for the treatment of animals in behavioural research and teaching. 2018. Animal Behaviour 135:I-X. DOI: 10.1016/j.anbehav.2017.10.001.

Guillemain M, Blanc R, Lucas C, Lepley M. 2008. Ecotourism disturbance to wildfowl in protected areas: historical, empirical and experimental approaches in the Camargue,

Guillemain M, Cavallo F, Massez G, George T, Baudet J-P, Gonzalez P, Ducasse V, Caillot E, Lecaplain B, Tison L, Piffeteau N, Artel J-P, Champagnon J. 2015a. Ringing does not appear to have an adverse effect on body mass immediately following capture in Common Teal Anas crecca. Wildfowl 65:64-74.

Guillemain M, Champagnon J, Gourlay-Larour M-L, Cavallo F, Brochet A-L, Hars J, Massez G, George T, Perroi P-Y, Jestin V, Caizergues A. 2015b. Blood and cloacal swab sampling for avian influenza monitoring has no effect on survival rates of free-ranging ducks. Ibis 157:743-753. DOI: 10.1111/ibi.12280.

Herring G, Gawlik DE, Cook MarkI, Beerens JM. 2010. Sensitivity of Nesting Great Egrets ( Ardea alba ) and White Ibises (Eudocimus albus ) to Reduced Prey Availability. The Auk 127:660-670. DOI: 10.1525/auk.2010.09144.

Hoffmann L, Hafner H, Salathe T. 1996. The Contribution of Colonial Waterbird Research to Wetland Conservation in the Mediterranean Region. Colonial Waterbirds 19:12. DOI: $10.2307 / 1521942$.

Hothorn T, Bretz F, Westfall P. 2008. Simultaneous Inference in General Parametric Models. Biometrical Journal 50:346-363. 
373 Ibáñez-Álamo JD, Sanllorente O, Soler M. 2012. The impact of researcher disturbance on nest 374 predation rates: a meta-analysis. Ibis $154: 5-14$. DOI: $10.1111 /$ j.1474-

375 919X.2011.01186.x.

376 Jones SL, Geupel GR (eds.). 2007. Beyond Mayfield: measurements of nest-survival data.

377

378

379

380

381

382

383

384

385

386

387

388

389

390

391

392

393

394

Camarillo, CA: Cooper Ornithological Society.

Klein ML, Humphrey SR, Percival HF. 1995. Effects of ecotourism on distribution of waterbirds in a wildlife refuge. Conservation Biology 9:1454-1465. DOI: 10.1046/j.15231739.1995.09061454.x.

Kronenberg J. 2014. Environmental impacts of the use of ecosystem services: case study of birdwatching. Environmental Management 54:617-630. DOI: 10.1007/s00267-014-03178.

Kuiken T, Wobeser G, Leighton F, Shirley I, Brown L. 1997. A modular tunnel-and-blind system to reduce investigator disturbance of breeding colonial waterbirds. Colonial Waterbirds 20:532-536. DOI: 10.2307/1521604.

Kushlan JA, Steinkamp MJ, Parsons KC, Capp J, Cruz MA, Coulter M, Davidson I, Dickson L, Edelson N, Elliot R, Erwin RM, Hatch SA, Kress S, Milko R, Miller S, Mills KL, Paul R, Phillips R, Saliva JE, Syderman B, Trapp J, Wheeler J, Wohl KD. 2002. Waterbird conservation for the Americas: The North American waterbird conservation plan, version 1.

Madsen J, Fox AD. 1995. Impacts of hunting disturbance on waterbirds-a review. Wildlife Biology 1:193-207.

Mayfield HF. 1975. Suggestions for calculating nest success. The Wilson Bulletin:456-466.

Peer] reviewing PDF | (2019:07:39461:1:1:NEW 4 Sep 2019) 
395 Miller SG, Knight RL, Miller CK. 1998. Influence of recreational trails on breeding bird 396 communities. Ecological Applications 8:162-169. DOI: 10.1890/1051-

397

398

399

400

401

402

403

404

405

406

407

408

409

410

411

412

413

414 Santoro S, Green AJ, Figuerola J. 2016. Immigration enhances fast growth of a newly

415 0761(1998)008[0162:IORTOB]2.0.CO;2.

Monti F, Duriez O, Dominici J-M, Sforzi A, Robert A, Fusani L, Grémillet D. 2018. The price of success: integrative long-term study reveals ecotourism impacts on a flagship species at a UNESCO site. Animal Conservation. DOI: 10.1111/acv.12407.

Navedo JG, Herrera AG. 2012. Effects of recreational disturbance on tidal wetlands: supporting the importance of undisturbed roosting sites for waterbird conservation. Journal of Coastal Conservation 16:373-381. DOI: 10.1007/s11852-012-0208-1.

Nisbet ICT. 2000. Disturbance, habituation, and management of waterbird colonies. Waterbirds: The International Journal of Waterbird Biology 23:312-332.

Piatt JF, Roberts BD, Hatch SA. 1990. Effects of human disturbance on breeding least and crested auklets at St. Lawrence island, Alaska. The Auk 107:342-350. DOI: $10.2307 / 4087618$

R Core Team. 2017. R: A Language and Environment for Statistical Computing. Vienna, Austria: R Foundation for Statistical Computing.

Romero LM, Romero RC. 2002. Corticosterone Responses in Wild Birds: The Importance of Rapid Initial Sampling. The Condor 104:129-135. DOI: 10.1650/00105422(2002)104[0129:CRIWBT]2.0.CO;2. established source population. Ecology 97:1048-1057. 
416 Saraux C, Le Bohec C, Durant JM, Viblanc VA, Gauthier-Clerc M, Beaune D, Park Y-H, 417 Yoccoz NG, Stenseth NC, Le Maho Y. 2011. Reliability of flipper-banded penguins as 418 indicators of climate change. Nature 469:203-206. DOI: 10.1038/nature09630.

419 Shaffer TL. 2004. A unified approach to analyzing nest success. The Auk 121:526-540. DOI:

420

421

422

423 424

425

426

427

428

429

430

431

432

433

434 435 436

437 10.1642/0004-8038(2004)121[0526:AUATAN]2.0.CO;2.

Shealer D, Haverland J. 2000. Effects of investigator disturbance on the reproductive behavior and success of Black Terns. Waterbirds 23:15-23.

Shugart GW, Fitch MA, Shugart VM. 1981. Minimizing investigator disturbance in observational studies of colonial birds: access to blinds through tunnels. The Wilson Bulletin 93:565-569.

Spotswood EN, Goodman KR, Carlisle J, Cormier RL, Humple DL, Rousseau J, Guers SL, Barton GG. 2012. How safe is mist netting? evaluating the risk of injury and mortality to birds: How safe is mist netting? Methods in Ecology and Evolution 3:29-38. DOI: 10.1111/j.2041-210X.2011.00123.x.

Stein A, Young MJ, Seddon PJ, Darby JT, van Heezik Y. 2017. Investigator disturbance does not reduce annual breeding success or lifetime reproductive success in a vulnerable longlived species, the yellow-eyed penguin. Biological Conservation 207:80-89. DOI: 10.1016/j.biocon.2017.01.013.

Tremblay J, Ellison LN. 1979. Effects of human disturbance on breeding of black-crowned night herons. The Auk 96:364-369.

Veen J. 1977. Functional and causal aspects of nest distribution in colonies of the Sandwich Tern (Sterna s. sandvicensis Lath.). Brill. 
438 Weiser EL, Lanctot RB, Brown SC, Alves JA, Battley PF, Bentzen R, Bêty J, Bishop MA, 439 Boldenow M, Bollache L, Casler B, Christie M, Coleman JT, Conklin JR, English WB,

440

441

442

443

444

445

446

447

448

449

450

451

452
Gates HR, Gilg O, Giroux M-A, Gosbell K, Hassell C, Helmericks J, Johnson A, Katrínardóttir B, Koivula K, Kwon E, Lamarre J-F, Lang J, Lank DB, Lecomte N, Liebezeit J, Loverti V, McKinnon L, Minton C, Mizrahi D, Nol E, Pakanen V-M, Perz J, Porter R, Rausch J, Reneerkens J, Rönkä N, Saalfeld S, Senner N, Sittler B, Smith PA, Sowl K, Taylor A, Ward DH, Yezerinac S, Sandercock BK. 2016. Effects of geolocators on hatching success, return rates, breeding movements, and change in body mass in 16 species of Arctic-breeding shorebirds. Movement Ecology 4. DOI: 10.1186/s40462-0160077-6.

Wickham H. 2016. ggplot2: Elegant Graphics for Data Analysis. Springer-Verlag New York. Wilson RP, McMahon CR. 2006. Measuring devices on wild animals: what constitutes acceptable practice? Frontiers in Ecology and the Environment 4:147-154. DOI: 10.1890/1540-9295(2006)004[0147:MDOWAW]2.0.CO;2. 


\section{Table $\mathbf{1}$ (on next page)}

Model selection table showing the ten best supported models to explain daily survival rate of Cattle Egrets, Little Egrets and Glossy Ibis nests in mixed-species heronry disturbed by banding operations in 2015 and 2016.

A total of 144 candidate models were tested, including the fixed effects of species, day since the first day of the survey, the position of the nest in a tree (height), zone in the colony (control vs. disturbed zone), the period of seven days following a disturbance (banding week), and second order interactions of interest. Year of survey and identification of the tree were considered as random variables for all candidate models. $K$ is the number of parameters in the model, $\log _{e}(L)$ is the value of the maximized log-likelihood function, $A I C_{c}$ is Akaike's Information Criterion adjusted for small samples, $\triangle A I C_{c}$ is the scaled value of $A I C_{c}$, and weight is the Akaike weight. 


\begin{tabular}{lccccc}
\hline Model & K & Loge(L) & AlCc & delta & weight \\
\hline Day+Height*Species+Species*Zone & 15 & -437.7 & 905.6 & 0.0 & 0.14 \\
Day+Height*Species & 12 & -441.1 & 906.2 & 0.6 & 0.10 \\
Day+Height+Species & 8 & -445.3 & 906.6 & 0.9 & 0.09 \\
Day+Height*Species+Species*Zone+BandingWeek & 16 & -437.4 & 907.1 & 1.4 & 0.07 \\
Day+Height+Species*Zone & 11 & -442.5 & 907.1 & 1.4 & 0.07 \\
Day+Height+Species+BandingWeek & 9 & -444.5 & 907.1 & 1.5 & 0.06 \\
Day+Height*Species+BandingWeek & 13 & -440.5 & 907.2 & 1.6 & 0.06 \\
Day+Height*Species+Zone & 13 & -440.9 & 908.0 & 2.3 & 0.04 \\
Day+Height+Species*Zone+BandingWeek & 12 & -442.0 & 908.1 & 2.5 & 0.04 \\
Day+Height*Species+Species*Zone+Zone*BandingWeek & 17 & -437.1 & 908.4 & 2.8 & 0.03 \\
\hline
\end{tabular}

1

2 Table 1. Model selection table showing the ten best supported models to explain daily survival rate of

3 Cattle Egrets, Little Egrets and Glossy Ibis nests in mixed-species heronry disturbed by banding

4 operations in 2015 and 2016. A total of 144 candidate models were tested, including the fixed effects of

5 species, day since the first day of the survey, the position of the nest in a tree (height), zone in the

6 colony (control vs. disturbed zone), the period of seven days following a disturbance (banding week),

7 and second order interactions of interest. Year of survey and identification of the tree were considered

8 as random variables for all candidate models. $K$ is the number of parameters in the model, $\log _{e}(L)$ is the

9 value of the maximized log-likelihood function, $A / C_{c}$ is Akaike's Information Criterion adjusted for small

10 samples, $\triangle A I C_{c}$ is the scaled value of $\mathrm{AIC}_{c}$, and weight is the Akaike weight. 


\section{Figure 1}

Capturing and marking Glossy Ibis chicks in a mixed heron colony

(A) Flushing adults when entering the colony. Cattle Egrets, Little Egrets, Squacco Herons and Glossy Ibis are identifiable. Photo credit: Tour du Valat. (B) Example of a capture of a Glossy Ibis chick in his nest. Photo credit: Jean-Emmanuel Roché. (C) Glossy Ibis chicks of approximately three weeks old, at the top of the trees. Note that two individuals fit a PVC and metal bands. Photo credit: Jean-Pierre Trouillas. (D) The floating blind used to monitor breeding success. Photo credit: Clément Pappalardo.
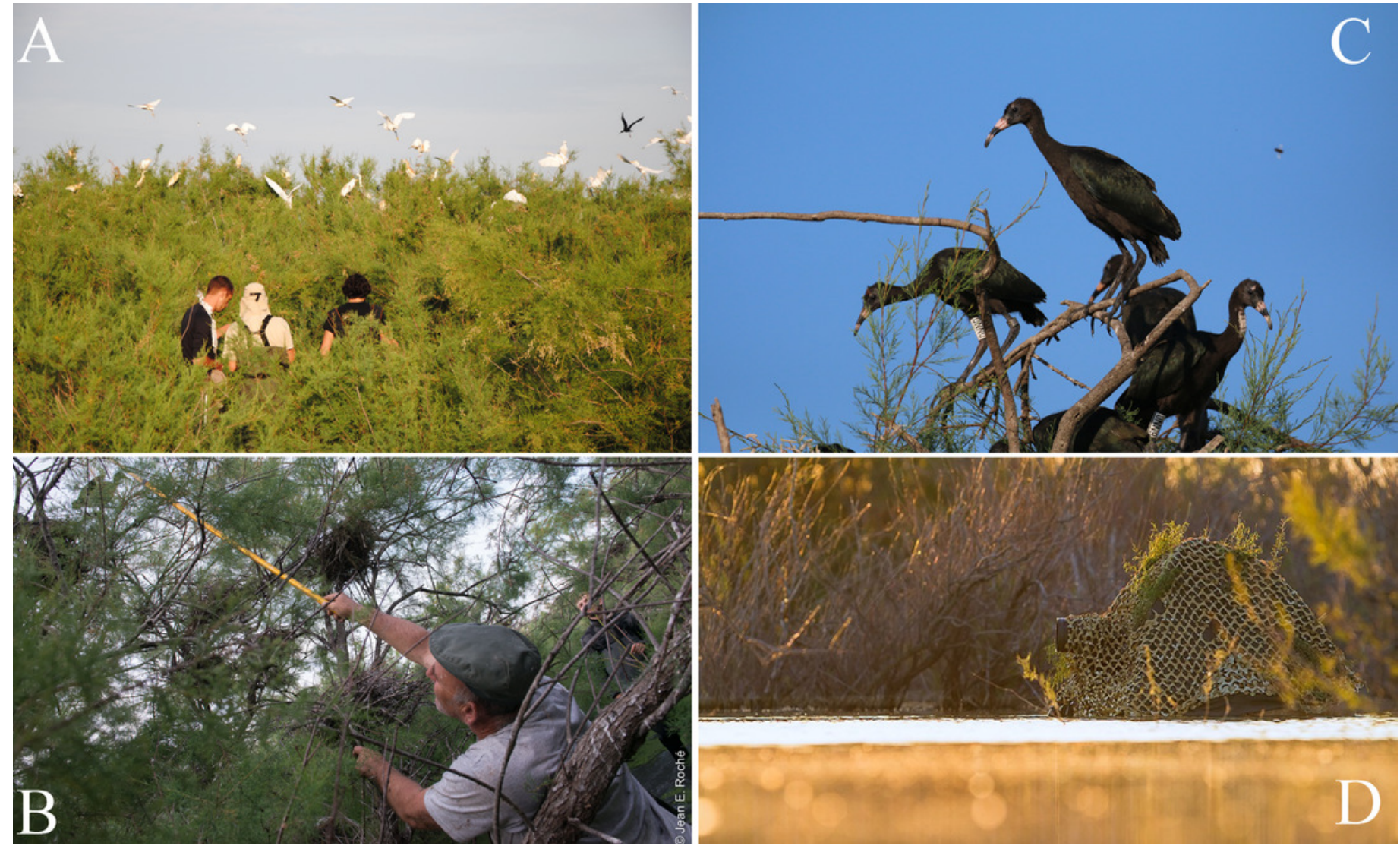
Figure 2

Number of nests monitored each year for each day of observation since the first incursion in the colony with a floating hide

The fate " 1 " corresponds to a nest seen active and " 0 " to an abandoned nest. The two annual banding operations are presented by vertical black lines and the seven days following a banding operation by the dark grey font.

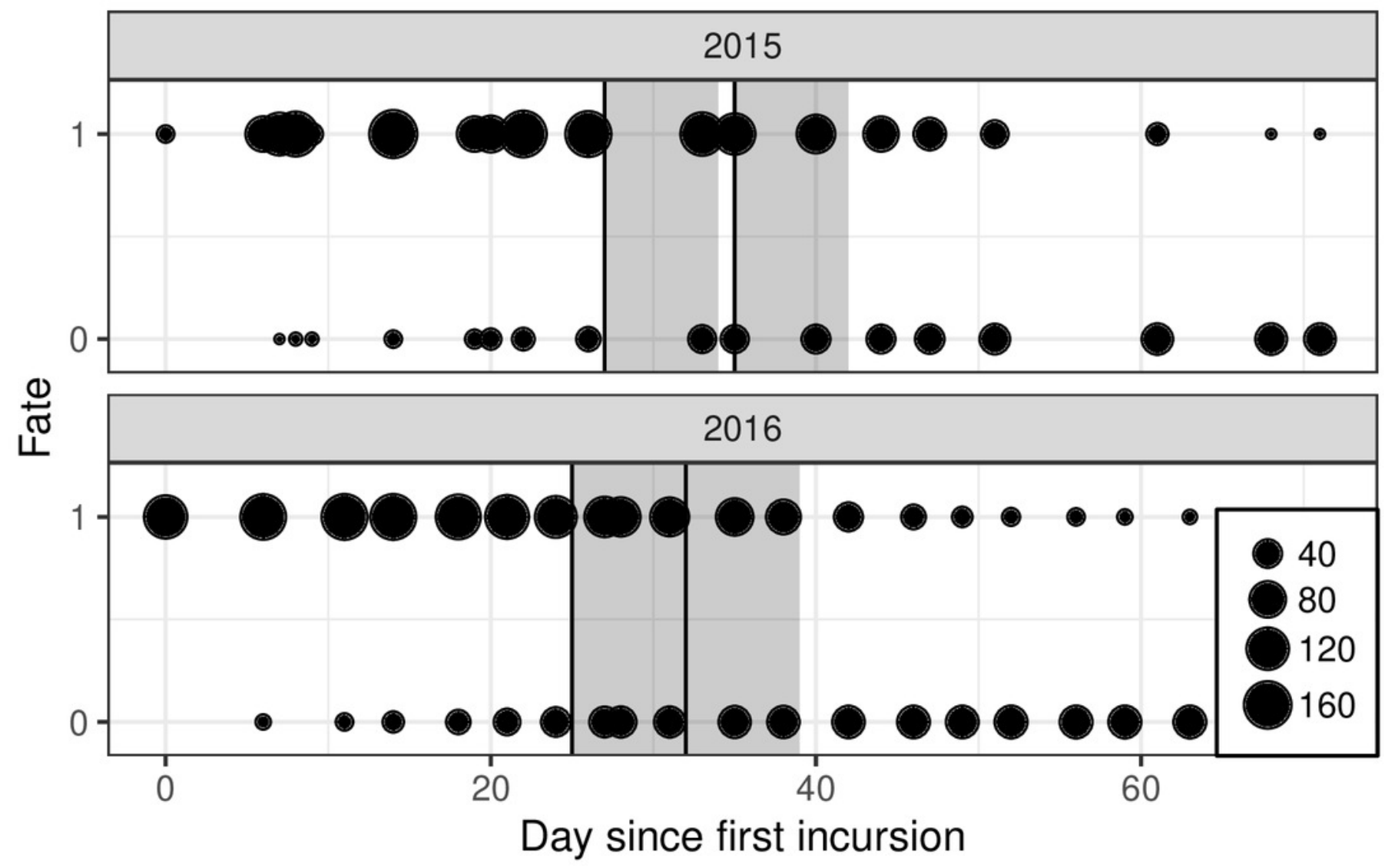


Figure 3

Effect of the height in tree on daily survival rate of nests of three species of tree-nesting waterbirds in a mixed-species heronry

"low" denotes for nests located between the water level and $1 \mathrm{~m}$, "med" for nests between $1 \mathrm{~m}$ and $2 \mathrm{~m}$, and "high" for nests above $2 \mathrm{~m}$. Estimates plotted in this figure are the predictions derived from the first model in Table 1. Sample sizes for each category are indicated at the top of the figure.

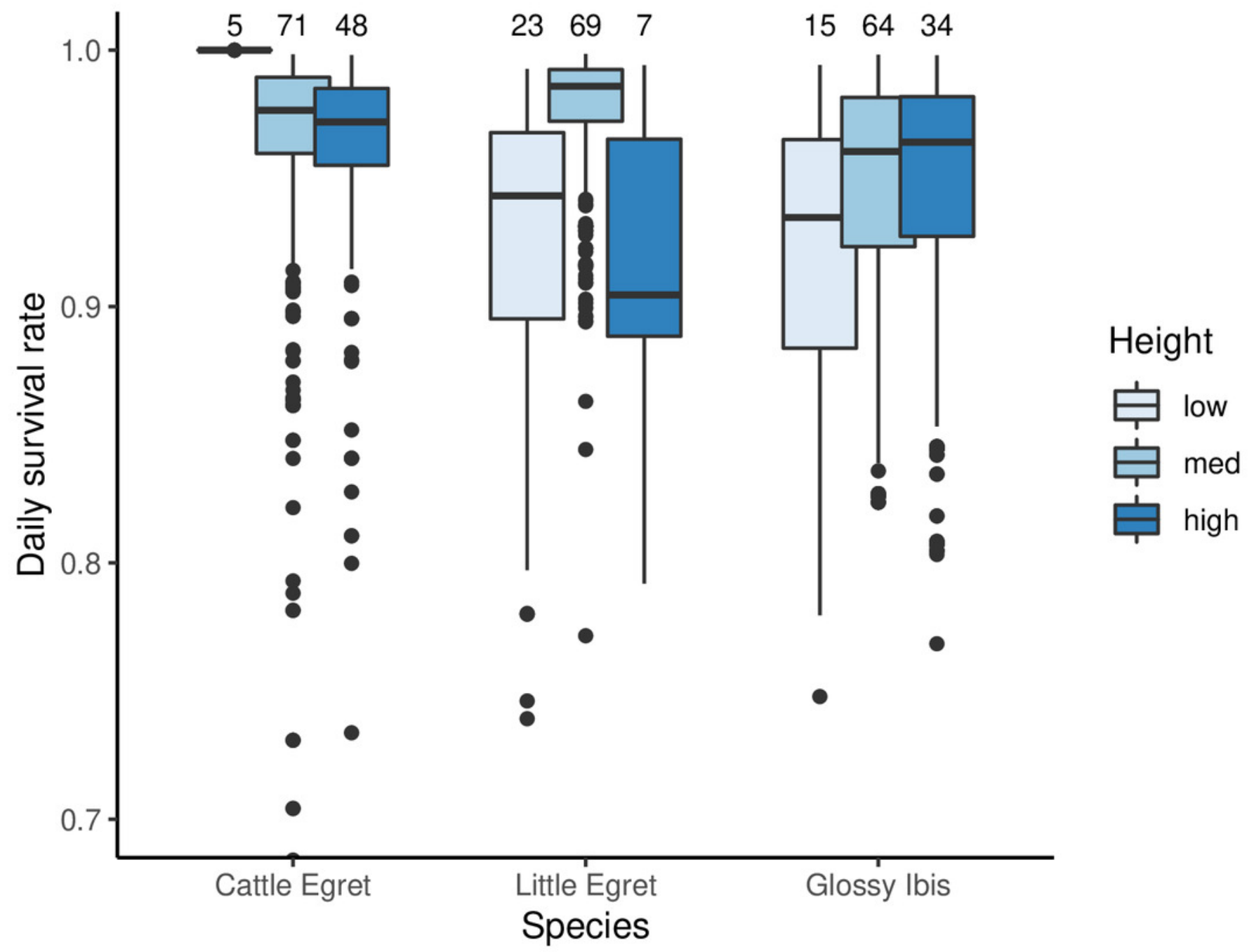


Figure 4

Effect of banding disturbance on daily survival rate of nests of three species of treenesting waterbirds in a mixed-species heronry.

Estimates plotted in this figure are the predictions derived from the first model in Table 1.

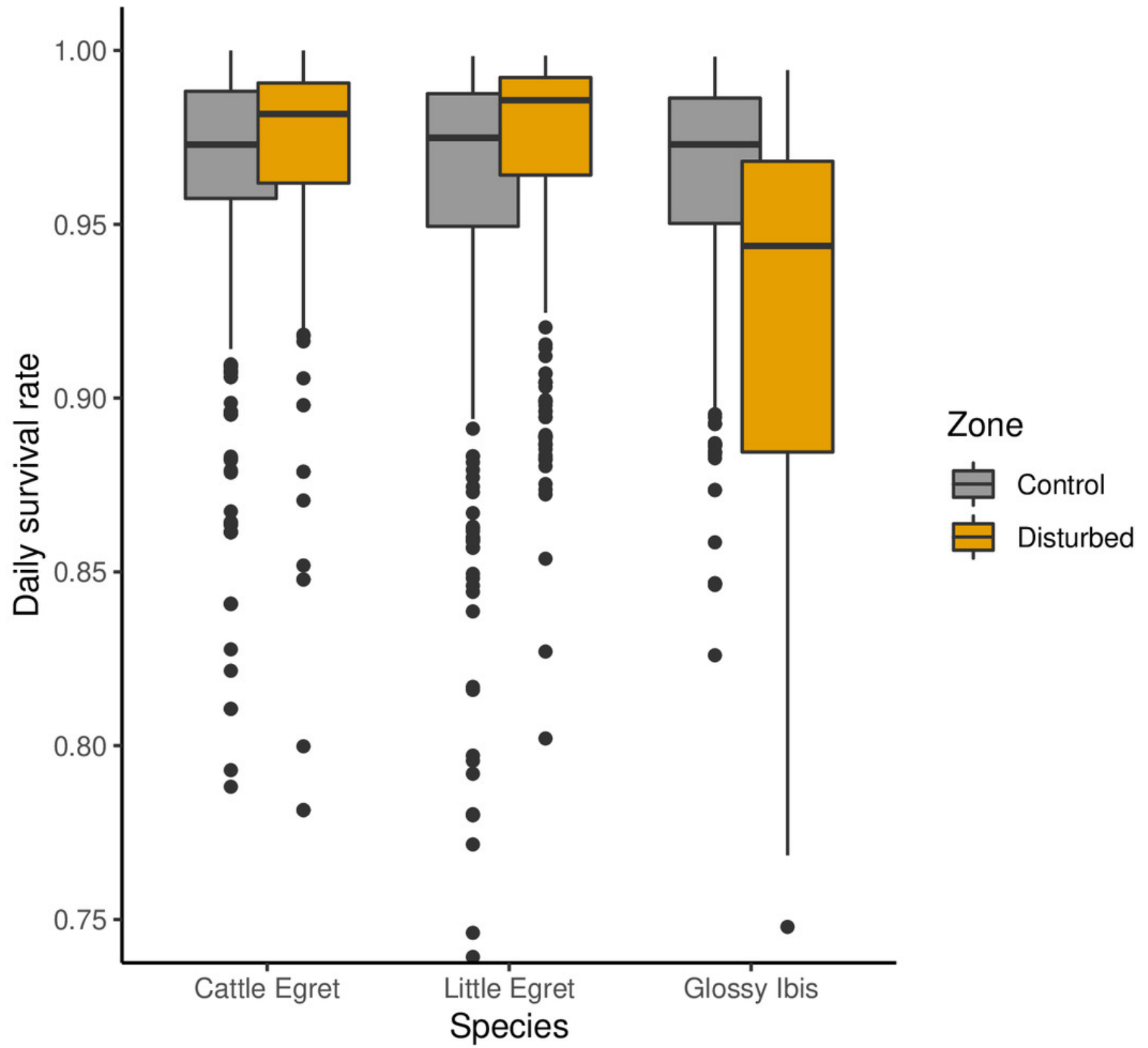

